\title{
Morphokinetics of mesenterial lymphatic node cell populations at exposure of gold nanoparticles in experiment
}

\author{
O.V. Zlobina, Irina O. Bugaeva, Galina N. Maslyakova, S.S. Firsova, Alla B. Bucharskaya, N.G. Khlebtsov*, \\ B.N. Khlebtsov *, L.A. Dykman* \\ Saratov State Medical University n.a. V.I. Razumovsky, Saratov, Russia \\ * Institute of Biochemistry and Physiology of Plants and Microorganisms of Russian Academy of Sciences, Saratov, Russia
}

Accepted 23 October 2012

Original Text in Russian (c) Zlobina O.V., Bugaeva I.O., Maslyakova G.N., Firsova S.S., Bucharskaya A.B., Khlebtsov N.G., Khlebtsov B.N., Dykman L.A., 2011, published in Saratov Journal of Medical Scientific Research 2011; 7(2): 354-357.

\begin{abstract}
The influence of gold nanoparticles with different size $(1-3 \mathrm{~nm}, 15 \mathrm{~nm}$ and $50 \mathrm{~nm})$ on the morphokinetics of mesenterial lymphatic node cell populations of healthy laboratory animals was investigated. It was established that the oral administration of gold nanoparticles caused the changes of morphokinetics of mesenterial lymphatic node cell populations. The morphological reorganizations in the mesenterial lymphatic nodes testified about activation of migration processes, the proliferation and differentiation processes of immunocompetent cells, which assumes the presence of immunomodulating action of gold nanoparticles.
\end{abstract}

Keywords: gold nanoparticles, mesenterial lymphatic nodes, cell populations.

Cite as Zlobina OV, Bugaeva IO, Maslyakova GN, Firsova SS, Bucharskaya AB, Khlebtsov NG, Khlebtsov BN, Dykman LA. Morphokinetics of mesenterial lymphatic node cell populations at exposure of gold nanoparticles in experiment. Russian Open Medical Journal $2012 ; 1: 0302$.

Correspondence to Galina N. Maslyakova. Address: Saratov State Medical University, 121, Bolshaya Kazachya str., Saratov, 410012, Russia. E-mail: gmaslyakova@yandex.ru

\section{Introduction}

To date, a large number of works were published concerning the use of gold nanoparticles (GN) in various fields of nanobiotechnology. Along with proven applications in recent years GN began to be used in various fields of nanomedicine for diagnostic and therapeutic purposes [1-3]. In particular, they are used as carriers for delivery of drugs, genetic material, antigens and as a proper drug or diagnostic agent for the treatment of cancer or rheumatoid arthritis [4]. Two drugs for intravenous administration - Aurlmmune ${ }^{\mathrm{TM}}$ and AuroLase $^{\mathrm{TM}}$ - have already passed the clinical trials [5]. Extensive material was also published about clinical trials of the drug Aurasol ${ }^{\circledR}$ in tablet form for the treatment of severe rheumatoid arthritis [4].

Almost simultaneously with the beginning of medical applications of nanoparticles the questions about their biodistribution, circulating in the blood stream, pharmacokinetics and excretion, as well as the possible toxicity of the whole organism or the level of cyto-and genotoxicity became urgent. Concerns about the possible effects of nanoparticles are not accidental. For example, in 1930-1950's particles of thorium dioxide size of 3-10 nm were widely used as a contrast agent ("thorotrast") in radiography. However, later it was found [5] that these particles can accumulate and remain in the body for decades, causing unwanted radiation effects. Recent publications of the toxicity of gold ultrananoparticles (about $1.5 \mathrm{~nm}$ ), and of significant accumulation of GN in liver and spleen of animals with very slow kinetics of elimination have appeared (see below). For gold nanorods original stabilizer molecules is cetyltrimethylammonium bromide (CTAB) [6], which is a known toxic surfactant in a free state.

Currently it was found that biological and toxic effects of nanomaterials depend on several critical parameters, critical of which is the size and shape of the particles, surface functionalization, the dose and route of administration. [4, 5, 7, 8]. The active research of the biodistribution and toxicity of GN was conducted during last 5 years. There was wide variation in the design of the experiment, including the size and shape of particles, methods of functionalization, types of animals, dose and route of administration of the particles. Accordingly, a large scatter of the data and findings was observed in the levels and kinetics of the biodistribution and toxicity assessments. At present the aspects of GN accumulation and morphological changes of immune system organs are not enough reflected in the literature.

The purpose of our work is to conduct a comprehensive analysis of morphokinetics of mesenteric lymph nodes of laboratory animals after oral administration of gold nanoparticles.

\section{Material and methods}

In experiment there were used colloidal gold particles with a diameter of 1-3 nm, $15 \mathrm{~nm}$ and $50 \mathrm{~nm}$ with gold concentration 57 $\mathrm{mkg} / \mathrm{ml}$, which were synthesized in the laboratory of nanobiotechnology of IBPPM Sciences (Saratov). The average size of GN was determined from electron microscopic images by Libra120 microscope (Carl Zeiss, Jena, Germany). Colloidal gold nanoparticles with a size of 15 and $50 \mathrm{~nm}$ were synthesized by recovering chloroauric acid ( $\mathrm{HAuCl} 4$, Sigma-Aldrich, USA) with 
sodium citrate by citrate method of Frens G. [1973]. Smallest particles 1-3 $\mathrm{nm}$ were obtained by special techniques described in [3].

For increasing the bioavailability and biocompatibility the nanoparticles were conjugated with polyethylene glycol, PEG-SH (Nektar, USA). Conjugation protocol was as follows. $45 \mathrm{mkl}$ of 0.2 $\mathrm{M}$ potassium carbonate and $500 \mathrm{ml} 5 \mathrm{mM}$ methyl polyethylene glycolthiol were added to $50 \mathrm{ml}$ of a suspension of nanoparticles. The conjugates were formed as a result of covalent binding of thiol groups to the surface of the gold shell. The reaction time was about 10 hours. The resulting conjugates were washed from excess of reaction products twice by centrifugation and resuspension in $0.9 \%$ sodium chloride solution.

The experiments were carried on 24 white outbred rats weighing 180-220 males. The animals in the experiment were kept in standard conditions on a normal diet. Animal experiments were conducted in accordance with the Geneva Convention «International Guiding principles for Biomedical Research Involving Animals» (Geneva, 1990). The animals were divided into 4 groups of 6 rats in each group. The first group was the control one; second, third and fourth groups were experienced. The rats in the experimental groups were administered orally gold nanoparticles every other day in dosage of $190 \mathrm{mg} / \mathrm{kg}$ of body weight for 15 days, as follows: first experimental group - $\mathrm{GN}$ with diameter of 1$3 \mathrm{~nm}, 2$ experimental group - GN with diameter of $15 \mathrm{~nm}, 3$ experienced group - GN with diameter $50 \mathrm{~nm}$. The rats in the control group were administered every other day $1 \mathrm{ml}$ of saline daily by mouth. Biopsy specimens were performed 24 hours after the last injection.

Counting the cellular elements (small, medium, large lymphocytes, plasma cells, immunoblasts and mitotic figures) were performed in different functional areas of the lymph node with an increase in the standard method $\times 100, \times 400, \times 1000$, using morphometric Bio Vision programs in 10 fields of view on the standard units of area $(6400 \mathrm{mkm})$. Photographing of histological preparations was performed using a digital camera SCOPETEK DCM. Statistical analysis of the results was conducted using the program «Statistica $6.0 »$.

\section{Results}

Control experiments showed that the distribution of different types of cells in different areas of the lymph nodes was inhomogeneously. Lymph follicles of cortical area does not contain the light centers, the small lymphocytes are dominated in them, and immunoblasts were found significantly fewer and practically absence of large lymphocytes, plasma cells and mast cells was detected. In the paracortical zone predominant cell elements were also small lymphocytes, medium lymphocytes were found in 5 times smaller than small lymphocytes, large lymphocytes and plasma cells were rare and immunoblasts and mast cells were absent. The small lymphocytes dominated in brain strands, but their absolute number was in 3 times lower than in the lymph follicles and paracortical zone. More often medium lymphocytes and plasma cells were found and in only a small number of large cells, immunoblasts, and mast cells was present.

At morphometric analysis of cell populations of the various functional areas of mesenteric lymph nodes significantly differenses from the control group were not found after administration of GN size 1-3 nm for 15 days. The number of small lymphocytes in the lymph follicles and paracortical zone amounted $62.3 \pm 1.6$ and $61.2 \pm 1.2$, respectively (in control group $-64.2 \pm 2.1$ and $60.1 \pm 1.2$, respectively). Average number of lymphocytes in the lymph follicles and paracortical area was $16.6 \pm 1.2$ and $4.3 \pm 0.8$, respectively (control $-18.2 \pm 0.4$ and $12.1 \pm 1.1$, respectively). The number of large lymphocytes in the lymph follicles and paracortical area was $0.5 \pm 0.01$ and $0.67 \pm 0.1$, respectively (control 0 and $0.75 \pm 0.1$, respectively). In the area of the brain strands the number of small lymphocytes was - 18.3 \pm 1.0 ; medium lymphocytes $-10.4 \pm 1.0$; plasma cells $-17.9 \pm 1.2$; immunoblasts $2.0 \pm 0.3$ (at the control $-20.2 \pm 1.3 ; 10.2 \pm 1.7 ; 15.3 \pm 0.6 ; 2.3 \pm 0.3$, respectively).

In the cortex of lymph follicles after administration GN size 15 and $50 \mathrm{~nm}$ the changes in the ratio of primary and secondary follicles were observed, which indirectly reveals about the increasing of lymphopoiesis. The increase of number of small (at $15 \mathrm{~nm}-71.2 \pm 1.2$; at $50 \mathrm{~nm}-83.3 \pm 1.7$ ), medium lymphocytes (at $15 \mathrm{~nm}-30.1 \pm 2.1, \mathrm{p}<0.001$, at $50 \mathrm{~nm}-35.3 \pm 1.0, \mathrm{p}<0.001)$, immunoblasts (at $15 \mathrm{~nm}-4.8 \pm 0.3$, at $50 \mathrm{~nm}-10.4 \pm 0.3$ ) was found compared with the control group (small lymphocytes - 64.2 \pm 2.1 , mean lymphocyte - $18.2 \pm 0.4$, immunoblasts - 2.5 \pm 0.3 ) at histological examination of morphokinetics of cell populations in the area (Figure 1).

In the paracortical area of mesenteric lymph nodes the increasing of number of small lymphocytes (at $15 \mathrm{~nm}-66.2 \pm 1.1$, at $50 \mathrm{~nm}-72.4 \pm 1.1$ ), medium lymphocytes (at $15 \mathrm{~nm}-30.1 \pm 2.1$, at $50 \mathrm{~nm}-35.3 \pm 1.0$ ), immunoblasts (at $15 \mathrm{~nm}-0.7 \pm 0.1$, at $50 \mathrm{~nm}$ $-2.9 \pm 0.1$ ) was noted in comparison with the control group (small lymphocytes $-60.1 \pm 1.2$, mean lymphocyte $-12.1 \pm 1.1$ ).

In the area of the brain strands of mesenteric lymph nodes the increasing of number of plasma cells was noted (at $15 \mathrm{~nm}$ $26.4 \pm 3.4$, at $50 \mathrm{~nm}-38.4 \pm 3.4$ ) compared with the control group (15.3 \pm 0.6$)$.

In all functional areas the increase of number of mitotic figures was found, especially in the lymph follicles (at $15 \mathrm{~nm}-4.0 \pm 0.3$, at $50 \mathrm{~nm}-4.6 \pm 0.1)$ compared to the control group $(0.2 \pm 0.01)$ (Figure 2).

The morphokinetics of cell elements of the mesenteric lymph nodes after administration of GNT within 15 days was characterized by activation of limfopoiesis and it carried a sizedependent manner, the most striking changes were observed after introduction of $\mathrm{GN}$ size 15 and $50 \mathrm{~nm}$.

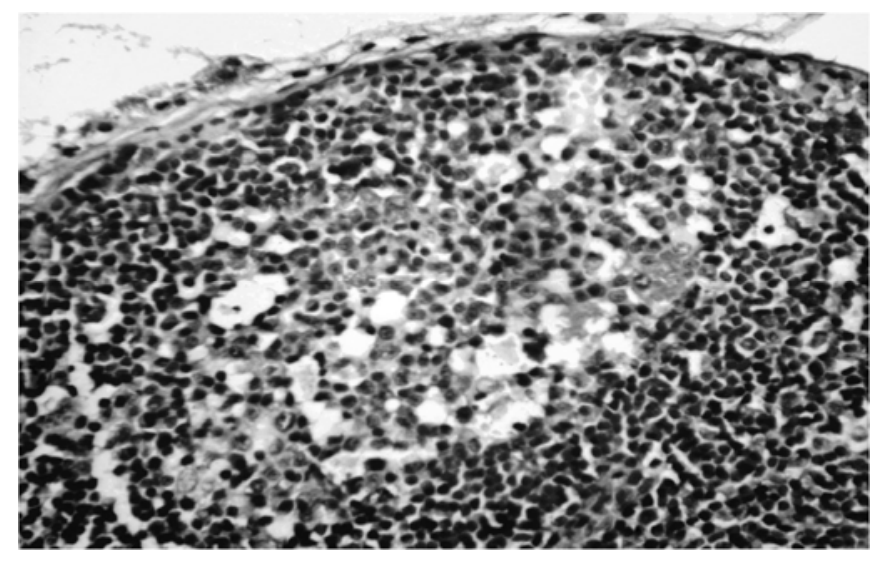

Fig. 1 Reactive lymph follicle center of cortex of lymph nodes after oral administration of gold nanoparticles of $50 \mathrm{~nm}$. 


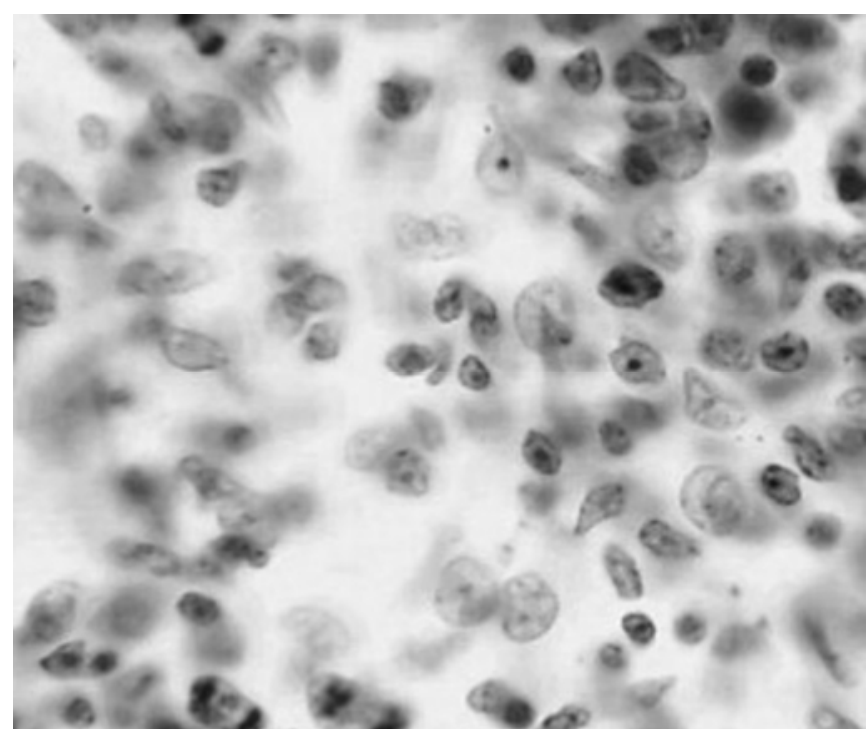

Fig. 2. Mitotic figures in the paracortical area of the lymph node with the introduction of gold nanoparticles of $50 \mathrm{~nm}$.

\section{Discussion}

The information about the impact of $\mathrm{GN}$ on lymphocyte proliferative activity isnot enough. Known, in particular, that the injection of colloidal gold may lead to its accumulation in the reticular cells of the lymphoid tissue, activation of cellular and humoral immunity of laboratory animals $[9,10]$. It is Interesting is that the cytotoxicity of GN has the size dependence - pronounced cytotoxicity was shown only for particles with a diameter of 1.4 $\mathrm{nm}$, but not for particle diameter of $15 \mathrm{~nm}$ [5].

In $[9,10]$ the properties of $G N$ to deliver antigens in vivo were studied and it was found thatGN enhanced phagocytic activity of macrophages and produced lymphocytes functionalization, which probably causes the GN immunomodulating effect [10].

Analyzing the results it can be noted that the dynamic changes were expressed in increasing of the number of small lymphocytes in lymphoid follicles and paracortical zone of lymph nodes. On histological preparations the area of paracortical zone of lymph nodes increased. In these terms of the pilot study the indications of proliferative activity increasing of lymphoid cells were locked. The increase of cells with mitotic figures was indirect confirmation of this, which reflected in germinal centers of lymphoid follicles and paracortical zone and brain strands in varying degrees.

The signs of increasing of differentiation and maturation of cellular elements in the lymph nodes of animals were observed. It was reflected in the increasing of number of immunoblasts and large lymphocytes in the structural zones of the lymph nodes. Distinct dynamics of the cell content of the germ, most notably in the brain strands were revealed.

The kinetics of cell populations in the lymph nodes was agreed with published data about the cytological and functional modifications of peripheral organs of immunogenesis under the influence of different effects. Dynamics of small, medium, large lymphocytes and immunoblasts in structural areas of lymph nodes is morphological evidence of activation of the migration, proliferation and differentiation of immune cells.

Therefore, the identifying changes in the quantitative rations of cell components of lymph nodes after administration of GN indicate on definite and distinct tendency to the development of the proliferation and differentiation processes of lymphocytes, which provides a basis for the assumption about stimulating effect of GN size of $15 \mathrm{~nm}$ and $50 \mathrm{~nm}$, especially on the immune cells of lymph nodes.

\section{Conclusion}

Summarizing the above data it can be concluded that oral administration of gold nanoparticles size of $15 \mathrm{~nm}$ and $50 \mathrm{~nm}$ for 15 days changes the morphokinetics of cell populations of mesenteric lymph nodes. Morphological adjustments in the mesenteric lymph nodes indicate about the activation of the migration, proliferation and differentiation of immune cells, which suggests immunomodulating activity of gold nanoparticles.

Conflict of interest: none declared.

\section{Reference}

1. Jain KK. A Handbook of Nanomedicine. Totowa, NJ: Humana/Springer; 2008.

2. Boisselier E, Astruc D. Gold nanoparticles in nanomedicine: preparations, imaging, diagnostics, therapies and toxicity. Chem Rev 2009; 38: 1759-1782 (PMID: 19587967) (doi: 10.1039/B806051G).

3. Dykman LA, Bogatyrev VA, Shchegolev SY, Khlebtsov NG. Gold nanoparticles: synthesis, properties and biomedical applications. Nauka Publ, Moscow, Russia, 2008 [Text in Russian].

4. Khlebtsov NG, Dykman LA. Biodistribution and toxicity of engineered gold nanoparticles: a review of in vitro and in vivo studies. Chem Soc Rev 2011; 40: 1647-1671 (doi: 10.1039/c0cs00018c) (PMID: 21082078).

5. Khlebtsov NG, Dykman LA. Biodistribution and toxicity of engineered gold. Russian nanotechnologies 2011; 6(1-2): 1-21 [Article in Russian].

6. Khlebtsov NG, Dykman LA. Optical properties and biomedical applications of plasmonic nanoparticles. J Quant Spectr Radiat Transfer 2010; 111: 1-35 (doi: 10.1016/j.jqsrt.2009.07.012).

7. Yen H-J, Hsu S-H, Tsai Ch-L. Cytotoxicity and immunological response of gold and silver nanoparticles of different sizes. Small 2009; 5: $1553-$ 1561 (PMID: 19326357) (doi: 10.1002/smll.200900126).

8. Alkilany AM, Murphy CJ. Toxicity and cellular uptake of gold nanoparticles: what we have learned so far? J Nanopart Res 2010; 12: 2313-2333 (PMCID: PMC2988217).

9. Staroverov SA, Aksinenko NM, Gabalov KP, Vasilenko OA Vidyasheva IV, Shchyogolev SYu, Dykman LA. Effect of gold nanoparticles on the respiratory activity of peritoneal macrophages. Gold Bulletin 2009; 42(2): 153-156.

10. Dykman LA, Staroverov SA, Bogatyrev VA, Shchyogolev SYu. Gold Nanoparticles as an Antigen Carrier and an Adjuvant. New York: Nova Publ., 2010.

\section{Authors:}

O.V. Zlobina - MD, Assistant, Department of Histology, Saratov State Medical University n.a. V.I. Razumovsky, Saratov, Russia;

Irina O. Bugaeva - MD, D.Sc., Professor, Head of Department of Histology, Saratov State Medical University n.a. V.I. Razumovsky, Saratov, Russia;

Galina N. Maslyakova - MD, D.Sc., Professor, Head of Department of Pathology Anatomy, Saratov State Medical University n.a. V.I. Razumovsky, Saratov, Russia;

S.S. Firsova - MD, Assistant, Saratov State Medical University n.a. V.I. Razumovsky, Saratov, Russia;

Alla B. Bucharskaya - PhD, Head of Department, Scientific-Educational Centre of Fundamental Medicine and Nanotechnologies, Scientific Research Institute of Fundamental and Clinical Uronephrology, Saratov State Medical University n.a. V.I. Razumovsky, Saratov, Russia; 
N.G. Khlebtsov - D.Sc., Professor, Head of Laboratory of Nanobiotechnology, Institute of Biochemistry and Physiology of Plants and Microorganisms of Russian Academy of Sciences, Saratov, Russia;

B.N. Khlebtsov - PhD, Senior Research Assistant, Laboratory of Nanobiotechnology, Institute of Biochemistry and Physiology of Plants and Microorganisms of Russian Academy of Sciences, Saratov, Russia;

L.A. Dykman - D.Sc., Leading Researcher, Laboratory of Immunochemistry, Institute of Biochemistry and Physiology of Plants and Microorganisms of Russian Academy of Sciences, Saratov, Russia. 